\title{
PEGTORALIS MINOR TRANSPLANT FOR PARALYSIS OF THE SERRATUS ANTERIOR
}

\author{
J. Paiva Chaves, Lisbon, Portugal \\ From the Colonial Hospital of Lisbon
}

The principal function of the serratus anterior [serratus magnus] muscle is to hold the vertebral border of the scapula against the thorax during elevation of the arm. When the muscle is paralysed, from an isolated lesion of the nerve to serratus anterior [long thoracic nerve; nerve of Bell], the vertebral border of the scapula stands away from the thorax, and

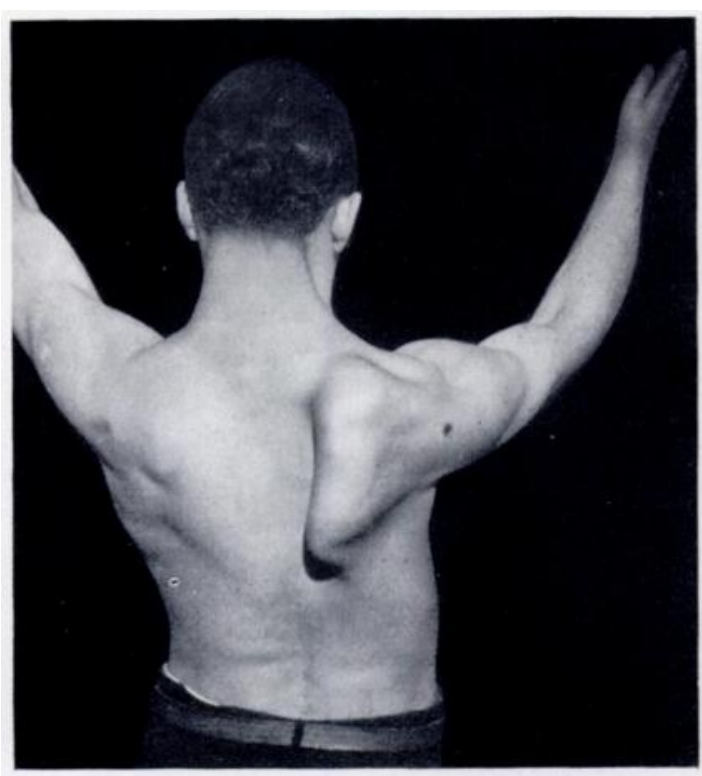

FIG. 1

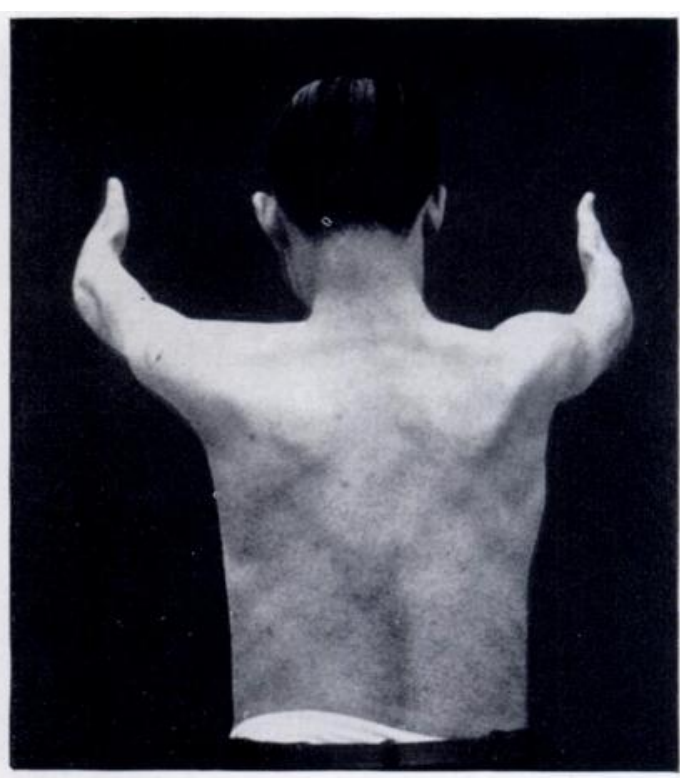

Fig. 2

Figure 1-Before operation. Typical winging of scapula on attempting to raise the arm. Figure 2 - Result six months after operation.

there is inability to raise the arm or to perform pushing movements. Recently we have carried out a muscle transplant in which the pectoralis minor was transferred to the vertebral border of the scapula; and although the method has been used in only one case the result has been so gratifying that a preliminary report seems justified.

Hitherto, operative treatment for this condition has been directed along one or more of the following lines: 1) fixation of the scapula to the ribs (Whitman 1932, Dickson 1937); 2) nerve anastomosis between the subscapular nerve and the nerve to serratus anterior (Skillern 1913) ; 3) transplant of a normal muscle to replace the paralysed serratus anterior. Muscles used have been the teres major (Hass 1937) and part of pectoralis major (Samter 1930).

Of these methods we considered that the most logical was to transfer a suitable muscle to replace the paralysed serratus anterior. But it seemed to us that a more suitable muscle for transfer than those previously described might be the pectoralis minor. A factor that weighed heavily in our selection of this muscle was our belief that when the serratus anterior 
was paralysed winging of the scapula was accentuated by contraction of the muscles attached to the coracoid process. We felt that transfer of the pectoralis minor from its coracoid insertion to the vertebral border of the scapula would be beneficial in two ways: it would control scapular displacement directly by affording an adequate substitute for the serratus anterior; and it would reduce the opposing action of the muscles attached to the coracoid process.

\section{CASE REPORT}

The patient was a hotel waiter aged twenty-one years. He complained that for about a year he had been unable to raise the right arm above the horizontal, either in abduction or flexion. The onset of the disability had followed an injection of antitetanus serum given on account of an abrasion of the left foot.

On examination he was found to have typical winging of the scapula, which was accentuated when he attempted to abduct or flex the arm (Fig. l). Total active abduction was limited to

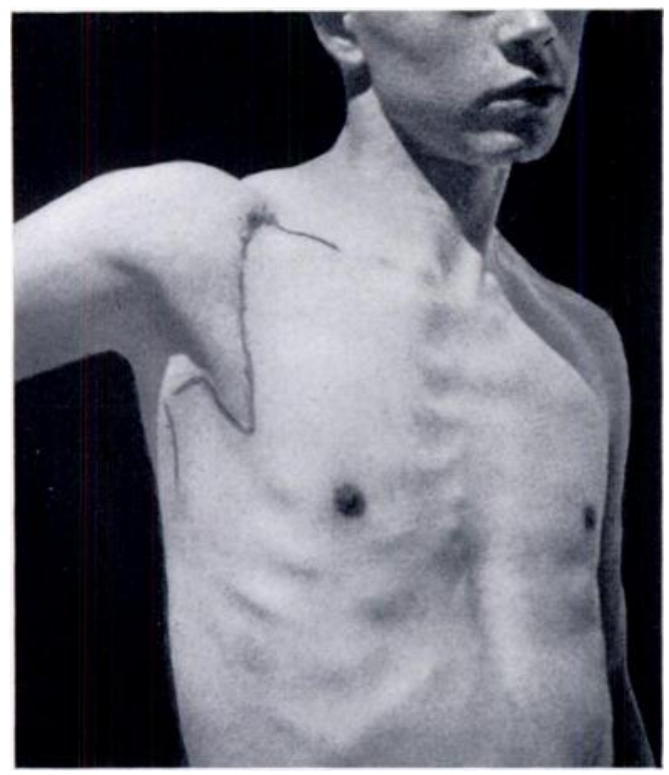

Fig. 3

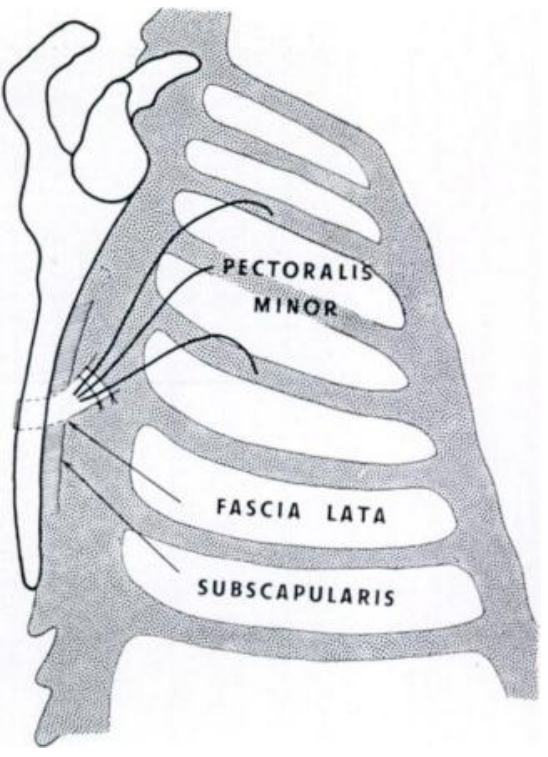

Fig. 4

Figure 3 - The incision. Figure 4-1)iagram to show course of the transplanted muscle. It was necessary to lengthen the tendon of pectoralis major by a strip of fascia lata to gain a secure. attachment to the vertebral border of the scapula.

45 degrees-all by gleno-humeral movement. Passive movement was full. Neurological examination showed no paralysis other than that of the serratus anterior.

Operation (February 2, 1950)-In planning the operation we had to bear in mind, first, the importance of avoiding injury to the large vessels and nerves; and secondly, the necessity of preserving the nerve supply to the pectoralis minor-a branch from the brachial plexus which passes behind the axillary artery and enters the deep face of the muscle near its costal attachments.

The incision was Z-shaped (Fig. 3). The tendon of the pectoralis minor was isolated and detached from the coracoid process together with a rectangle of the common insertion of the coraco-brachialis and biceps. The upper part of the belly of pectoralis minor was freed. The subscapularis covering the anterior surface of the scapula was cleared as far back as its posterior limit near the vertebral border of the scapula. Two holes were made through the

VOL. 33 B, NO, 2, MAY 1951 
bone with a chisel, near the vertebral margin of the scapula at the junction of its upper and middle thirds. Since the pectoralis minor was not sufficiently long to permit its direct attachment to the scapula its tendon was prolonged by a strip of fascia obtained from the thigh. This was passed as a loop through the two chisel holes in the scapula, and sutured to the tendon of the pectoralis minor (Fig. 4). The fascia was further anchored by suturing it down to the fascia covering the subscapularis.

At the conclusion of the operation the limb was immobilised in the transverse plane of the body by a thoraco-brachial plaster. This was discarded after six weeks and active rehabilitation was begun. The result has been entirely satisfactory (Fig. 2). Winging of the scapula has been overcome, and almost a full range of shoulder movement has been regained.

Comment-The efficiency of an operation cannot be judged from a single case. Nevertheless the result obtained certainly justifies further trial of the method.

\section{REFERENCES}

Dickson, F. D. (1937): Fascial Transplants in Paralytic and Other Conditions. Journal of Bone and Joint Surgery, 19, 405.

Hass, J. (1931): Muskelplastik bei Serratuslähmung. Zeitschrift für Orthopädische Chirurgie, $\mathbf{5 5 , 6 1 7 .}$

SAMTER (1930): Sur le traitement opératoire de la paralysis du grand dentelé. (Abstract) Journal de Chirgurgie, 35, 299.

Skillern, P. G., Jr. (1913): Serratus magnus palsy with proposal of a new operation for intractable cases. Annals of Surgery, 57, 909.

Wнiтмas, A. (1932): Congenital Elevation of Scapula and Paralysis of Serratus Magnus Muscle. Journal of the American Medical Association, 99, 1332. 